\title{
Validation of models for prediction of chloride ingress in concrete exposed in de-icing salt road environment
}

\section{Luping Tang*}

Department of Civil and Environmental Engineering, Chalmers University of Technology,

SE-412 96 Gothenburg, Sweden

Fax: + 46 31-772-1993

E-mail: tang.luping@chalmers.se

and

CBI Swedish Cement and Concrete Research Institute, Box 857, SE-501 15 Borås, Sweden

Fax: + 46 33-13-45-16

E-mail: tang.luping@cbi.se

*Corresponding author

\section{Anders Lindvall}

Central Laboratory, Thomas Concrete Group AB, Ringögatan 14, SE-417 07 Gothenburg, Sweden Fax: +46 31-744-23-02

E-mail: anders.lindvall@tcg.nu

\begin{abstract}
This paper presents the results from validation of models for prediction of chloride ingress in concrete exposed in de-icing salt road environment. Three models including the simple error-function complement (ERFC) model, the DuraCrete model and the ClinConc model, were evaluated using the measurement data collected from both the field exposure site after over ten years exposure and the real road bridges after 25-30 years in service. The sensitivity of input parameters in each model is analysed. The results show that, among different input parameters, the age factor is the most sensitive one. The simple ERFC model significantly overestimates chloride ingress. The DuraCrete model, if the input parameters are properly selected, may give a reasonably good prediction, otherwise often underestimates chloride ingress. The ClinConc model in general gives fairly good predictions for chloride ingress in de-icing salt road environment with heavy traffic at high speed.
\end{abstract}

Keywords: cement; chloride; concrete; corrosion; de-icing salt; diffusion; durability; modelling; road environment; service life.

Reference to this paper should be made as follows: Tang, L. and Lindvall, A. (xxxx) 'Validation of models for prediction of chloride ingress in concrete exposed in de-icing salt road environment', Int. J. Structural Engineering, Vol. X, No. Y, pp.000-000. 
Biographical notes: Luping Tang obtained his $\mathrm{PhD}$ in 1996 in Building Materials at Chalmers University of Technology, Gothenburg, Sweden. Since then, he worked at SP Technical Research Institute of Sweden and later CBI Swedish Cement and Concrete Research Institute. He is currently a Professor in Building Materials at Chalmers University of Technology, Gothenburg, Sweden. His main research interest is durability of concrete and electrochemical applications in concrete, especially with regard to chloride transport and chloride induced corrosion of steel in concrete. He is the primary developer of the rapid chloride migration (RCM) test, the chloride in concrete (ClinConc) model and the rapid corrosion measurement (RapiCor) instrument.

Anders Lindvall obtained his PhD in 2003 in Building Materials at Chalmers University of Technology, Gothenburg, Sweden. Afterwards, he worked at Chalmers as Post Doctor and Assistant Professor for many years. His research involves modelling environmental actions and their influence on durability of reinforced concrete structures. He is currently working at the Central Laboratory, Thomas Concrete Group AB in Gothenburg.

\section{Introduction}

Chloride induced corrosion of reinforcement in concrete is still one of the main concerns regarding durability and service life of reinforced concrete structures. Prediction of chloride ingress in concrete is one of the important parts in durability design of reinforced concrete structures exposed to the chloride environments. There are many models published in the literature for prediction of chloride ingress in concrete. A critical review can be found in ChlorTest (2005). A general requirement for prediction models is that the model can predict reliable results which are reasonably in agreement with the field measured data. Nowadays more and more field data are available (Lindvall, 2001; Tang, 2003; Tang and Utgenannt, 2007) in Sweden from both the real concrete structures and field exposure sites. These data are very useful for validation of the prediction models for their applicability with respect to exposure climate in order to apply the models in the durability design and redesign of concrete structures. This paper presents the results of validation of the models for the chloride (de-icing salt) road environment using the available field data.

\section{Models for prediction of chloride ingress}

Although there are many models, the most frequently referred one in the literature is the simple error-function complement (ERFC) model based on an error function solution to Fick's second law:

$$
C(x, t)=C_{\mathrm{i}}+\left(C_{\mathrm{s}}-C_{\mathrm{i}}\right) \cdot \operatorname{erfc}\left(\frac{x}{2 \cdot \sqrt{D_{\mathrm{a}} \cdot t}}\right) \approx C_{\mathrm{s}} \cdot \operatorname{erfc}\left(\frac{x}{2 \cdot \sqrt{D_{\mathrm{a}} \cdot t}}\right)
$$

where $C_{\mathrm{i}}$ is the initial chloride content in the concrete (usually this chloride content is negligible), $C_{\mathrm{s}}$ is the surface chloride content, $x$ is the depth, $D_{\mathrm{a}}$ is the apparent diffusion 
coefficient, $t$ is the exposure duration. In this model the parameters $C_{\mathrm{s}}$ and $D_{\mathrm{a}}$ are assumed constant during the whole period of exposure.

It has been found that the curve-fitted apparent diffusion coefficient $D_{\mathrm{a}}$ is time-dependent (Maage et al, 1995). A certain modification for time-dependent $D_{\text {a }}$ was proposed by the consortium of the European project DuraCrete (2000) and later fib (2006):

$$
D_{\mathrm{a}}=k_{\mathrm{e}} \cdot k_{\mathrm{c}} \cdot D_{\mathrm{RCM}} \cdot\left(\frac{t_{0}}{t}\right)^{n}
$$

where: $k_{\mathrm{e}}$ is the environmental factor, $k_{\mathrm{c}}$ is the factor considering the influence of curing on $D_{\mathrm{RCM}}$, the chloride diffusion coefficient measured by the rapid chloride migration (RCM) test according to the Nordic standard NT BUILD 492 (NordTest, 1999), $t_{0}$ is the concrete age at which $D_{\mathrm{RCM}}$ is measured, $t$ is the exposure duration and $n$ is the age factor describing the time-dependency of the effective diffusion coefficient.

In the past years, the mechanism-based model called ClinConc was developed from original numerical one to a more engineering one (Tang, 2007, 2008). This model basically calculates the free chloride concentration in the pore solution using the following equation:

$$
\frac{c-c_{i}}{c_{\mathrm{s}}-c_{i}}=\operatorname{erfc}\left(\frac{x}{2 \sqrt{\frac{\xi_{D} D_{\mathrm{RCM} 6 \mathrm{~m}}}{1-n^{\prime}} \cdot\left(\frac{t_{6 \mathrm{~m}}}{t}\right)^{n^{\prime}} \cdot\left[\left(1+\frac{t_{\mathrm{ex}}}{t}\right)^{1-n^{\prime}}-\left(\frac{t_{\mathrm{ex}}}{t}\right)^{1-n^{\prime}}\right]} \cdot t}\right)
$$

where $c, c_{\mathrm{s}}$ and $c_{i}$ are the concentration of free chlorides in the pore solution at depth $x$, at the surface of the concrete and initially in the concrete, respectively, $D_{\text {RCM6m }}$, is the chloride diffusion coefficient measured by the RCM test at the concrete age 6 months $\left(t_{6 \mathrm{~m}}\right), n^{\prime}$ is the age factor accounting for the decrease of diffusivity with exposure time $t$ due to the time-dependent chloride binding, $t_{\mathrm{ex}}$ is the concrete age at start of exposure, and $\xi_{\mathrm{D}}$ is the factor bridging the laboratory measured $D_{\mathrm{RCM} 6 \mathrm{~m}}$ to the initial apparent diffusion coefficient for the actual exposure environment. The detailed description and calculation equations for the factor $\xi_{\mathrm{D}}$ are published elsewhere (Tang, 2007). After the calculation of free chloride distribution, the total chloride distribution can then be calculated using the following equation:

$$
C=\frac{\varepsilon \cdot\left(c_{\mathrm{b}}+c\right)}{B_{\mathrm{c}}} \times 100
$$

where $C$ is the total chloride content, in mass\% of binder, $\varepsilon$ is the water accessible porosity at the age after the exposure, $B_{c}$ is the cementitious binder content, in $\mathrm{kg} / \mathrm{m}^{3}$ concrete, and the bound chloride $c_{\mathrm{b}}$, in $\mathrm{g} / \mathrm{l}$ (pore solution), can be obtained with the help of chloride binding isotherm. The detailed procedure for calculation of $c_{\mathrm{b}}$ is described elsewhere (Tang, 2007).

The ClinConc model was developed initially for submerged marine environment, where the chloride solution is constantly in contact with the concrete surface and no 
carbonation or hydroxide leaching was taken into account. When the model is used for de-icing road environment, certain modifications are needed.

First of all, the surface free chloride concentration under the de-icing highway environment is unknown and can vary from zero to near saturation in a short period. Secondly, the time-dependent chloride binding due to further hydration and pore saturation under the marine environment may not be the same extent under the de-icing road environment. Thirdly, the existing $\mathrm{CO}_{2}$ under the road environment will more or less react with alkali components in concrete, resulting in decreased $\mathrm{pH}$ value in the pore solution, which will in turn reduce chloride binding, although this decreased $\mathrm{pH}$ value cannot be detected by phenolphthalein agent. It is in lack of data for quantifying the above influencing factors, especially the third one - hydroxide leaching or partial carbonation and its effect on chloride binding. In this study, therefore, the following two modifications were made after some preliminary trials using the data of chloride profiles from the field site (Tang and Utgenannt, 2007):

1 the time-dependent factor of chloride binding was considered as $1 / 3$ of that for the submerged marine environment

2 a factor considering hydroxide leaching or partial carbonation was added to the parameter for chloride binding.

Figure 1 Sensitivity of various input parameters (see online version for colours)

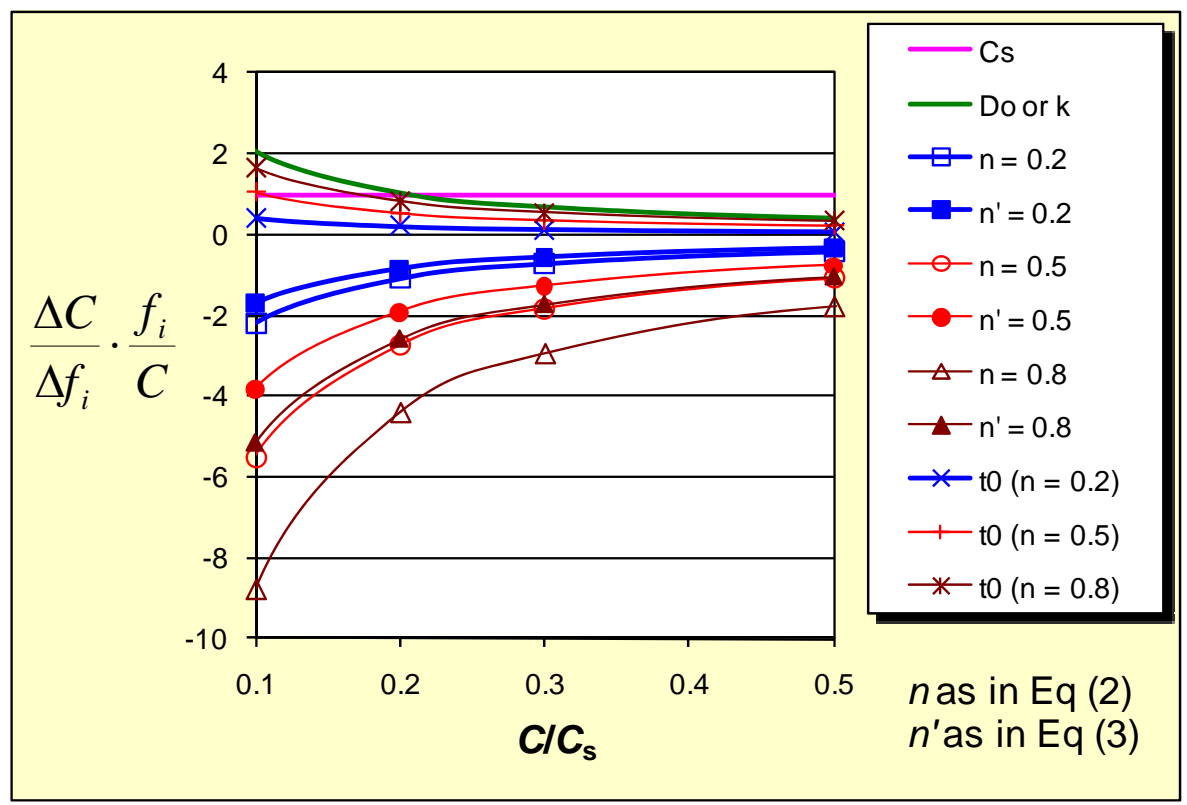

\section{Sensitivity of the input parameters}

Since the initial chloride concentration $C_{\mathrm{i}}$ or $C_{\mathrm{i}}$ in equation (1) or (3) only changes the vertical position of a chloride distribution profile, but not influences the shape of the 
profile, it is reasonable to assume it as 0 . The sensitivity of various input parameters can then be analytically evaluated by differentiating each parameter in concern. Figure 1 shows the results of sensitivity of various input parameters. It can be seen that, among different parameters, the age factor $n$ is the most sensitive one, especially when its value is larger than 0.2. The sensitivity of all the other input parameters is dependent on the ratio $C / C_{\mathrm{s}}$, except for parameter $C_{\mathrm{s}}$, which is constantly equal to 1 , independent of other parameters.

\section{Validation against the long-term field data}

\subsection{Data over ten years' exposure in a road environment}

Since 1996, a large number of reinforced concrete specimens with different qualities have been exposed at the field exposure by Highway 40 between Borås and Gothenburg in the west part of Sweden, where de-icing salt was intensively used on the road due to severe winter climate. Figure 2 shows the specimens exposed at the field site. Chloride profiles in some of concrete specimens were measured after 1, 2, 5 and 10 years of exposure. These field data are valuable for validation of prediction models. The detailed description of the field exposure site and concrete specimens was published elsewhere (Tang and Utgenannt, 2007).

Figure 2 Concrete blocks at the field exposure site by highway rv40 (see online version for colours)

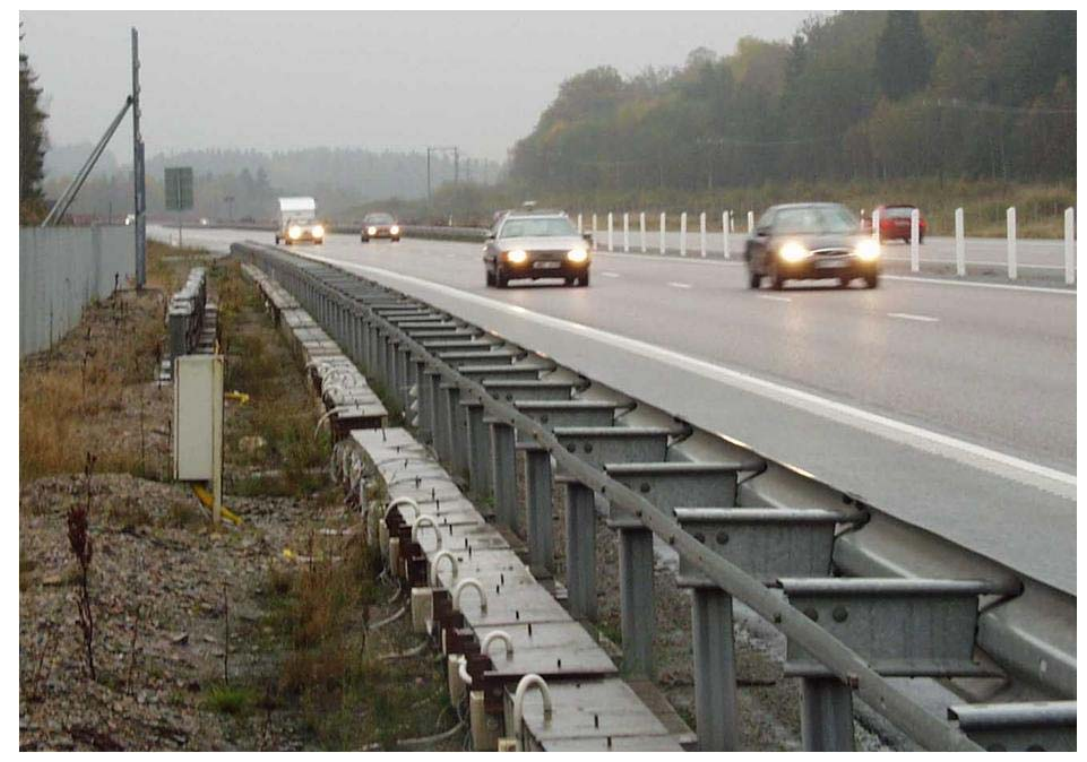

Two types of concrete with water-binder ratio w/b 0.4, one ordinary SRPC concrete and another SRPC+5\% SF (silica fume), were used for validation. According to the laboratory test results (Tang, 2003), the value of $D_{\text {RCM6m }}$ for SRPC concrete with $w / b 0.4$ is $12.2 \times 10^{-12} \mathrm{~m}^{2} / \mathrm{s}$ and for SRPC $+5 \%$ SF with $w / b 0.4$ is $4.43 \times 10^{-12} \mathrm{~m}^{2} / \mathrm{s}$. The values of 
$D_{\text {RCM6m }}$ were used for all the models although in (DuraCrete, 2000) the concrete age $t_{0}$ is specified as 28 days. If the same $n$ value is assumed for the period from 28 days to six months, there should, however, be no difference in the $D_{\mathrm{a}}$ values calculated using $D_{\text {RCM28d }} \cdot\left(t_{28 \mathrm{~d}}\right)^{n}$ and $D_{\text {RCM6m }} \cdot\left(t_{6 \mathrm{~m}}\right)^{n}$.

In the DuraCrete (2000) guidelines, there is no value of input parameters directly available for de-icing salt road environment. Although some values were suggested by the Swedish Association of Concrete (Betongföreningen, 2007), it has been demonstrated that these values resulted in a significant underestimation of chloride ingress (Tang and Utgenannt, 2007). The values for atmospheric zone were, therefore, used in this evaluation, as listed in Table 1. An initial chloride content $C_{\mathrm{i}}=0.02 \%$ of binder was assumed in the modelling.

The same $C_{\mathrm{s}}$ value in the DuraCrete model was used in the simple ERFC model.

The environmental data used in the ClinConc model include the free chloride concentration $C_{\mathrm{s}}=1.5 \mathrm{~g} / \mathrm{l}$ and the annual average temperature $T=10^{\circ} \mathrm{C}$ (excluding the freezing period). The initial free chloride concentration in the pore solution was assumed as $0.002 \mathrm{~g} / \mathrm{l}$. The concrete age at the start of exposure, $t_{\mathrm{ex}}=28$ days. Other parameters are similar to that used in the previous studies (Tang, 2007).

Table 1 Input data used in the DuraCrete and the simple ERFC models

\begin{tabular}{|c|c|c|}
\hline Binder type & $100 \%$ SRPC & $95 \%$ SRPC + 5\% SF \\
\hline Curing factor $\mathrm{k}_{\mathrm{c}}$ & \multicolumn{2}{|c|}{0.79} \\
\hline Environmental factor $\mathrm{k}_{\mathrm{e}}$ & \multicolumn{2}{|c|}{0.68} \\
\hline $\mathrm{A}_{\mathrm{s}, \mathrm{c}}$, mass $\%$ of binder & 2.57 & 3.23 \\
\hline Age factor $n$ & 0.65 & 0.79 \\
\hline
\end{tabular}

Figure 3 Modelled and measured chloride profiles for SRPC concrete (see online version for colours)
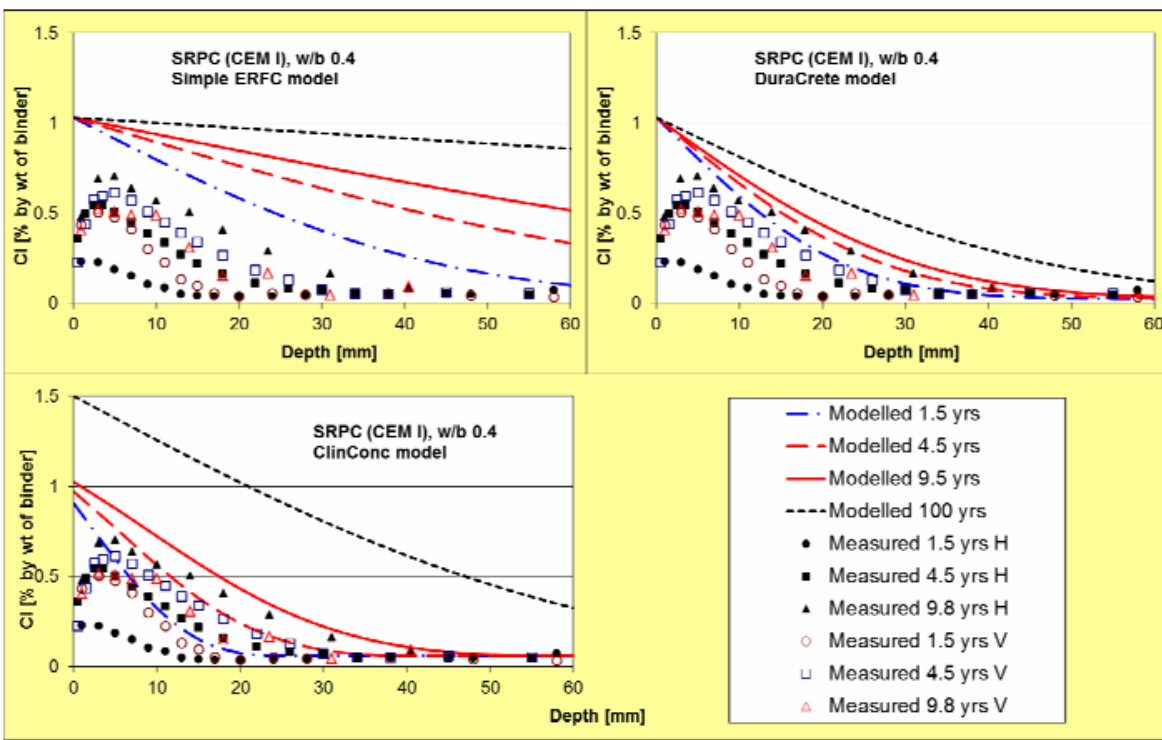
Figure 4 Modelled and measured chloride profiles for SRPC +5\% SF concrete (see online version for colours)

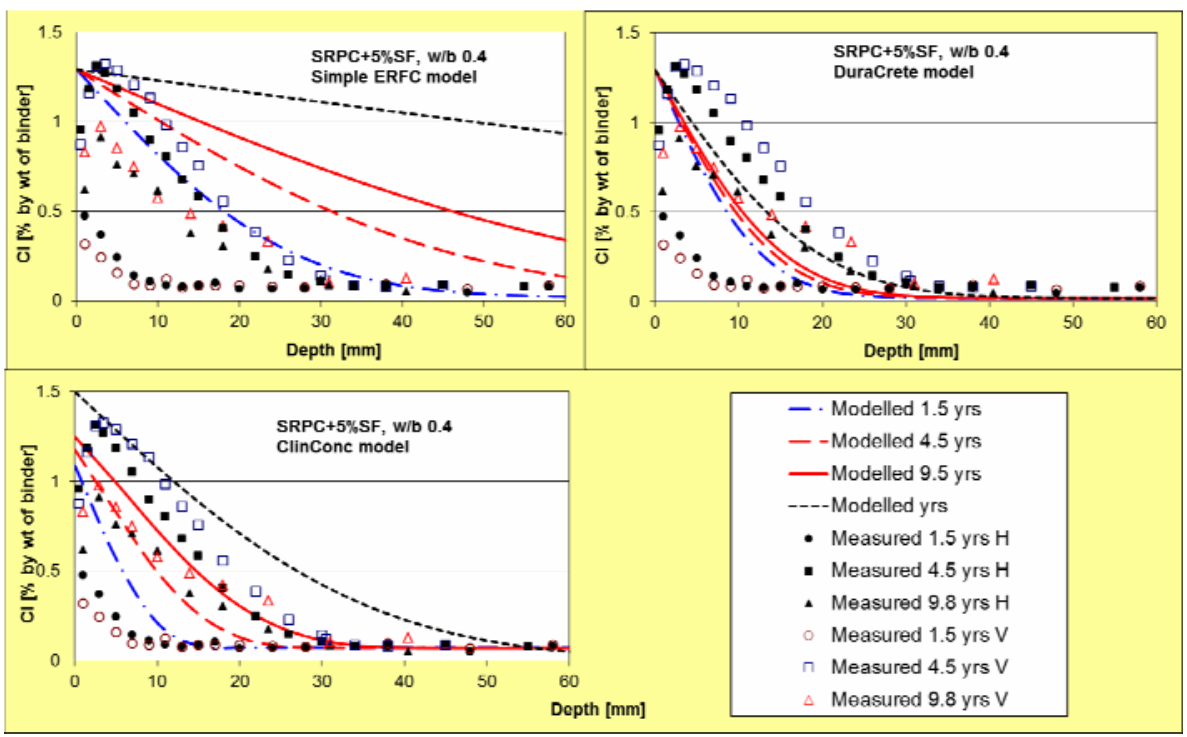

The predicted and measured chloride profiles are shown in Figure 3 and Figure 4, where ' $H$ ' denotes the field data measured from the horizontal exposure surface and ' $V$ ' denotes the field data measured from the vertical exposure surface. It can be seen that none of the models can predict the chloride ingress precisely, especially when the five-year profiles are higher than the ten-year profiles for the silica fume concrete. The simple ERFC model significantly overestimates the chloride ingress in both types of concrete. The DuraCrete model overestimates the chloride ingress in SRPC concrete but underestimates that in silica fume concrete. In addition, the predicted profiles from 1.5 to 10 years are very close each other, not really reflects the reality. The ClinConc model reveals relatively better predictions although the five-year profile for silica fume concrete is far from the measured ones. Measurement uncertainty in the field data can also be the reason to this unpredictable case.

\subsection{Data over 30 years exposure from real structures}

In the end of 1990's, a number of road bridges of 25-30 years old around Gothenburg in Sweden were sampled for chloride ingress profiles (Lindvall, 2001). The detailed information about bridges and samplings are published elsewhere (Lindvall, 2001). Some of the profiles taken from the concrete elements near the heavy traffic lane were used for validation of the models. The concrete for use in bridges during that period was produced with Swedish SRPC. According to the measurement using the RCM test on the specimens taking from deeper parts of the cores the $D_{\text {RCM }}$ values are in the range of 8.6-16.6 $\times 10^{-12} \mathrm{~m}^{2} / \mathrm{s}$ (Lindvall, 2001). Considering the concrete age (25-30 years), we can assume that the water-binder ratio $w / c$ is in a range of $0.4-0.5$. Therefore, the mixes with SRPC and $w / c 0.4$ and 0.5 , respectively, were used in the modelling with $D_{\text {RCM6m }}=8.6 \times 10^{-12} \mathrm{~m}^{2} / \mathrm{s}$ for $w / c 0.4$ and $16.6 \times 10^{-12} \mathrm{~m}^{2} / \mathrm{s}$ for $w / c 0.5$. According to the 
results reported by Frederiksen et al. (1997), the $D_{\text {RCM28d }}$ value for Swedish SRPC concrete with $w / b 0.4$ and 0.5 is $14.4 \times 10^{-12} \mathrm{~m}^{2} / \mathrm{s}$ and $18.6 \times 10^{-12} \mathrm{~m}^{2} / \mathrm{s}$, respectively. The $D_{\text {RCM6m }}$ values were used in the simple ERFC model and naturally in the ClinConc model, while both the values of $D_{\text {RCM6m }}$ and $D_{\text {RCM28d }}$, correspondently $t_{0}=0.5$ years (6 months) and 0.077 years (28 days), respectively, were used in the DuraCrete model for comparison. Other parameters used are the same as in 4.1. The results from three cases are presented.

\subsubsection{Case 1 - Bridge O 978}

Figure 5 shows a view of Bridge O 978 over Highway 40 between Borås and Gothenburg with heavy traffic and high speed (> $100 \mathrm{~km} / \mathrm{h}$ ). Figure 6 shows the sampling positions. The chloride profiles used for validation were taken from the lower part of the first column against Gothenburg (as marked as ' $U$ '), approximately $3 \mathrm{~m}$ from the traffic lane. The marks 'FB'/'FG' and 'MB'/'MG' indicate the sampling positions where the vehicles come from (as ' $F$ ') Borås/Gothenburg and where the vehicles pass the column towards (as ' $M$ ') Borås/Gothenburg. The modelled results are shown in Figure 7. The simple ERFC model significantly overestimates the chloride ingress, although the $D$ value measured in the 25 years old concrete was used in the model. The ClinConc model with $w / b 0.4$, the DuraCrete model with $D_{\mathrm{RCM} 28 \mathrm{~d}} w / b 0.5$ and with $D_{\mathrm{RCM} 6 \mathrm{~m}} w / b 0.4$ revealed relatively good prediction, while the ClinConc model with $w / b 0.5$ and the DuraCrete model with $D_{\text {RCM6m }} w / b 0.5$ give an overestimated prediction, and the DuraCrete model with $D_{\text {RCM28d }} w / b 0.4$ underestimates the chloride ingress.

Figure 5 A view of Bridge O 978 (25 years old), taken from the west (see online version for colours)

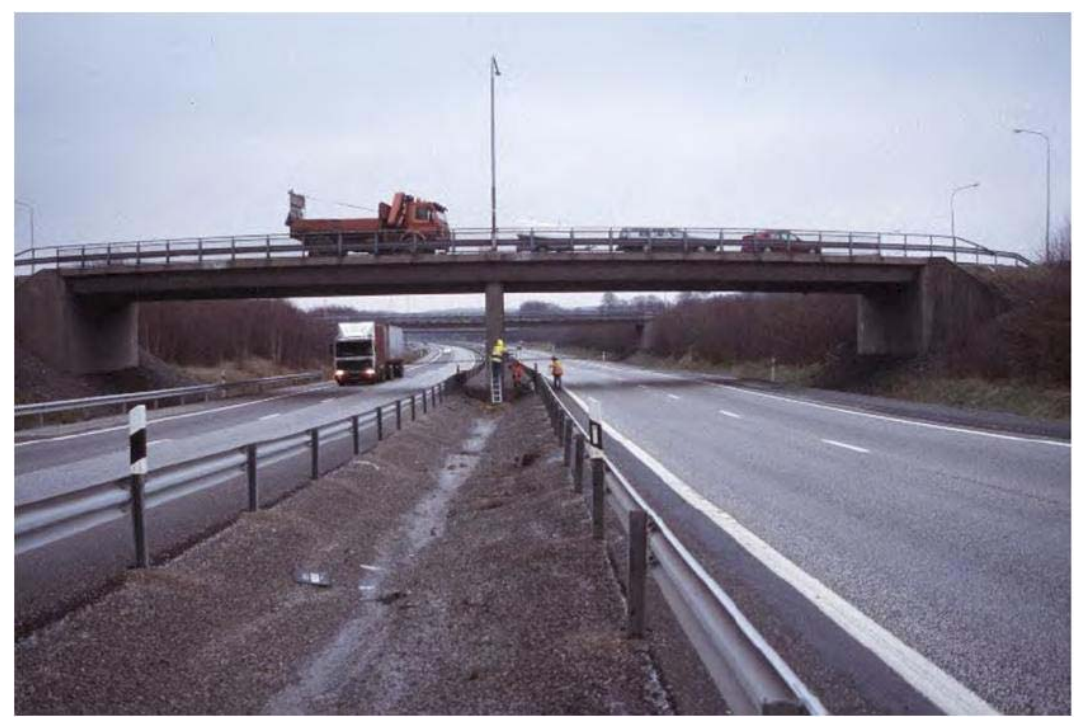

Source: Lindvall (2001) 
Figure 6 Sampling positions on Bridge O 978

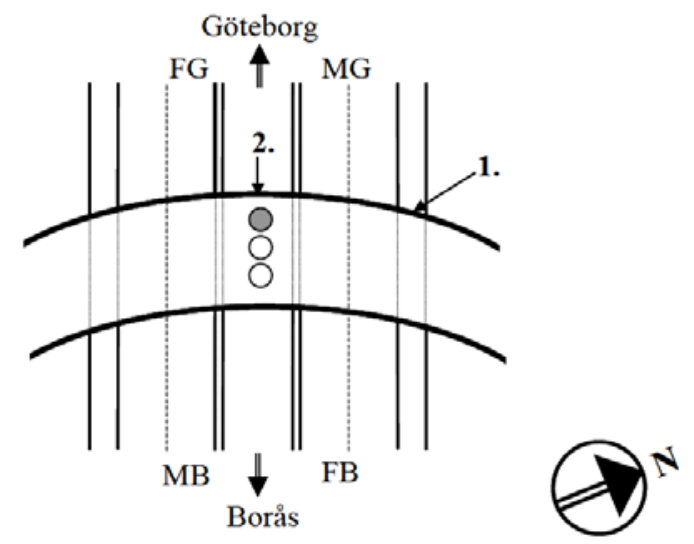

Note: The examined column is marked with grey and the locations of the places where the cores have been taken from the side-beam are marked with 1 and 2.

Source: Lindvall (2001)

Figure 7 Modelled and measured chloride profiles in a 25 years old road bridge (see online version for colours)

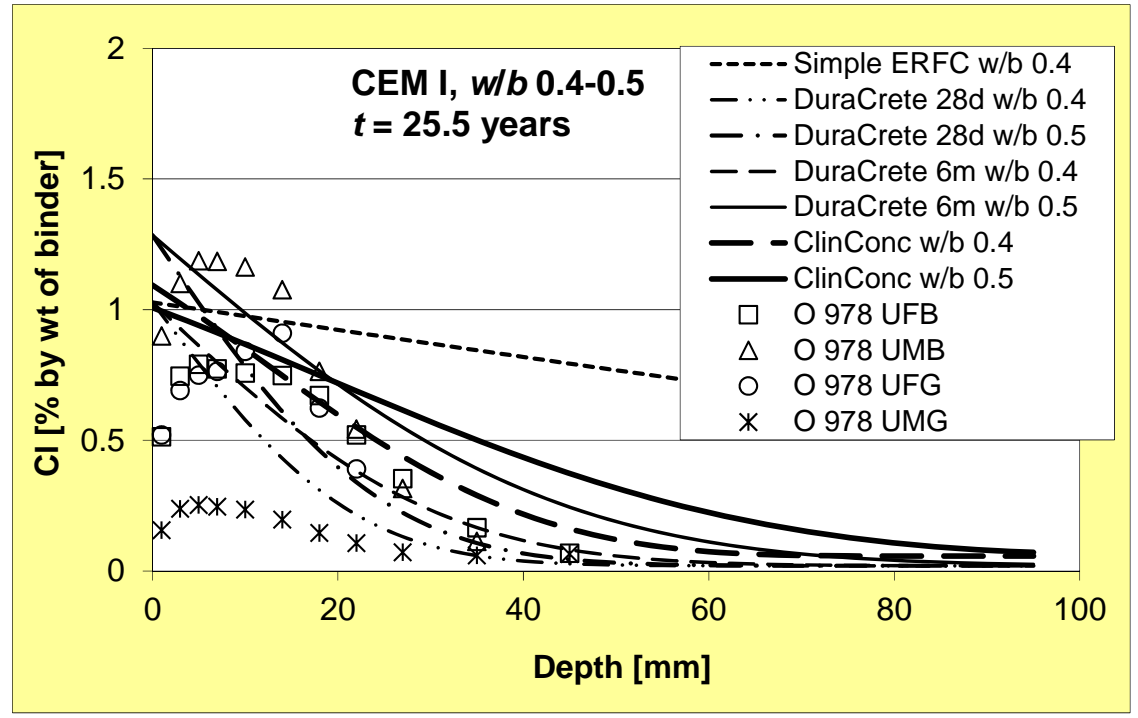

\subsubsection{Case 2 - Bridge O 951}

Figure 8 shows a view of Bridge O 951 over the highway between Gothenburg and Malmö with heavy traffic and high speed (> $100 \mathrm{~km} / \mathrm{h}$ ). Figure 9 shows the sampling positions. The Chloride profiles used for validation were taken from the lower part of the first column against Malmö (as marked by 'U'), approximately $2 \mathrm{~m}$ from the traffic lane. The marks 'FG'/'FM' and 'MG'/'MM' indicate the sampling positions where the 
vehicles come from (as ' $\mathrm{F}$ ') Gothenburg/Malmö, and where the vehicles pass the column towards (as ' $M$ ') Gothenburg/Malmö, as illustrated in Figure 9. The modelled results are shown in Figure 10. It can be seen that the ClinConc model fairly well predicted the three profiles but not the highest one, which was taken from the first column on the side receiving the splashed water from the vehicles from Malmö. The DuraCrete model with $D_{\text {RCM6m }} w / b 0.5$ gives also fairly good prediction, but with other input parameters underestimates the chloride ingress this bridge column. The simple ERFC model still significantly overestimates the chloride ingress.

Figure 8 A view of Bridge O 951 (27 years old), taken from the south (see online version for colours)

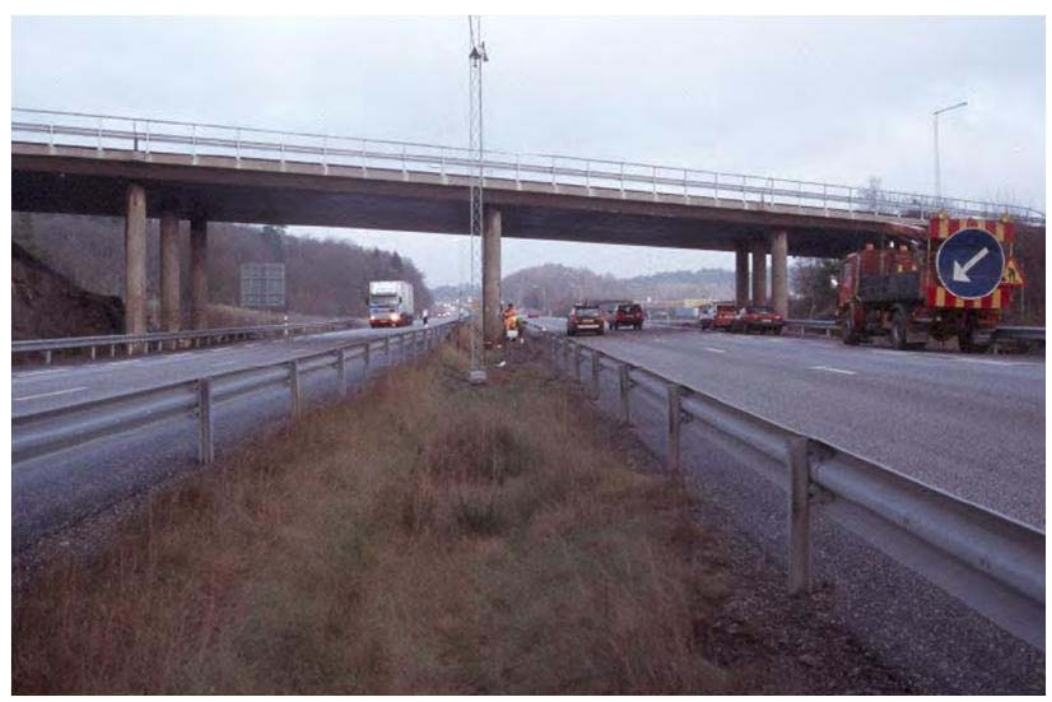

Source: Lindvall (2001

Figure 9 Sampling positions on Bridge O 951

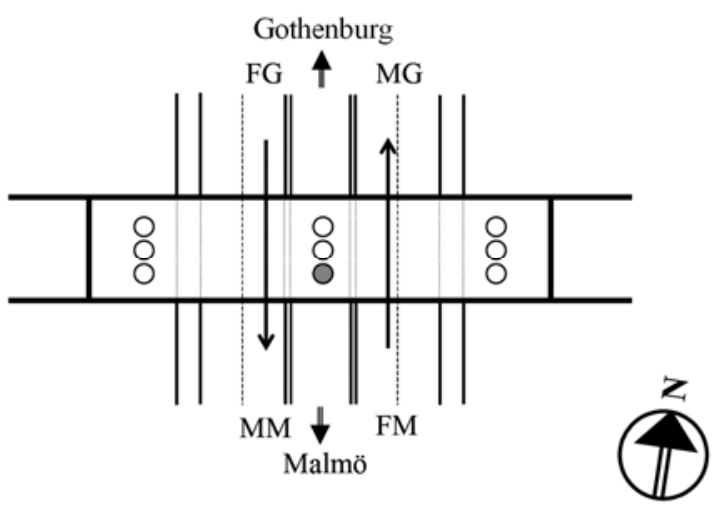

Note: The examined column is marked with grey.

Source: Lindvall (2001) 
Figure 10 Modelled and measured chloride profiles in a 27 years old road bridge (see online version for colours)

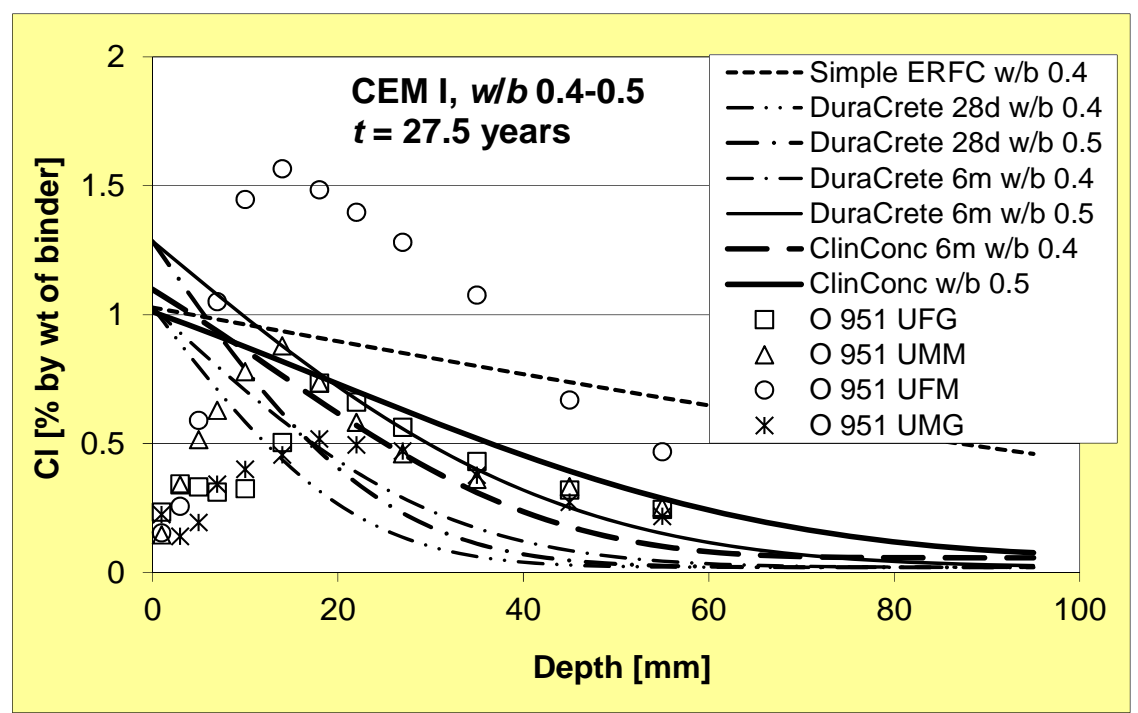

\subsubsection{Case 3 - Bridge O 670}

Figure 11 shows a view of the highway bridge $\mathrm{O} 670$ with heavy traffic and high speed (> $100 \mathrm{~km} / \mathrm{h}$ ). Figure 12 shows the general plan and sampling spots.

Figure 11 A view of Bridge O 670 over river Nordre Älv (30 years old), taken from the northwest (see online version for colours)

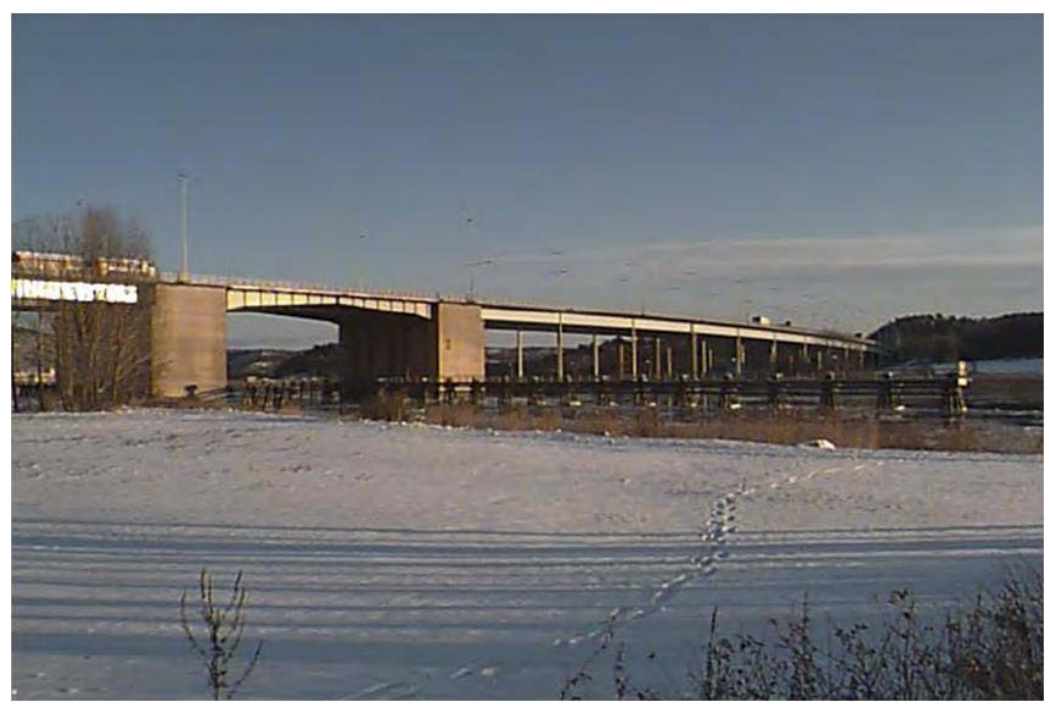

Source: Lindvall (2001) 
Figure 12 General plan showing the sampling spots on Bridge $\mathrm{O} 670$ (see online version for colours)
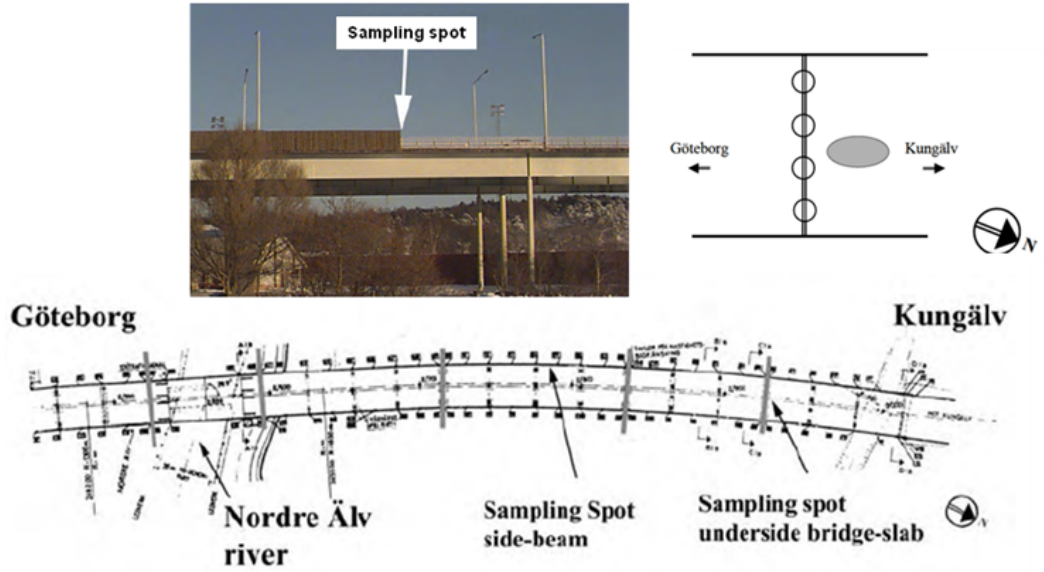

Source: Lindvall (2001)

Two chloride profiles were used for validation and the results are shown in Figure 13. The chloride profile marked ' $\mathrm{O} 670 \mathrm{KK}+\mathrm{RH}$ ' was taken from the side beam approximately $3 \mathrm{~m}$ from the traffic lane and profile marked ' $\mathrm{O} 670 \mathrm{KU} 2$ ' was taken from the underside of the pavement slab near the joint where the leakage of water was visible. It can be seen from the results that the ClinConc model reveals fairly good prediction for the chloride ingress in this concrete bridge. Similar to those in Figure 10, the DuraCrete model with $D_{\text {RCM6m }} w / b 0.5$ gives also fairly good prediction, but with other input parameters underestimates the chloride ingress. The simple ERFC model again significantly overestimates the chloride ingress.

Figure 13 Modelled and measured chloride profiles in a 30 years old road bridge (see online version for colours)

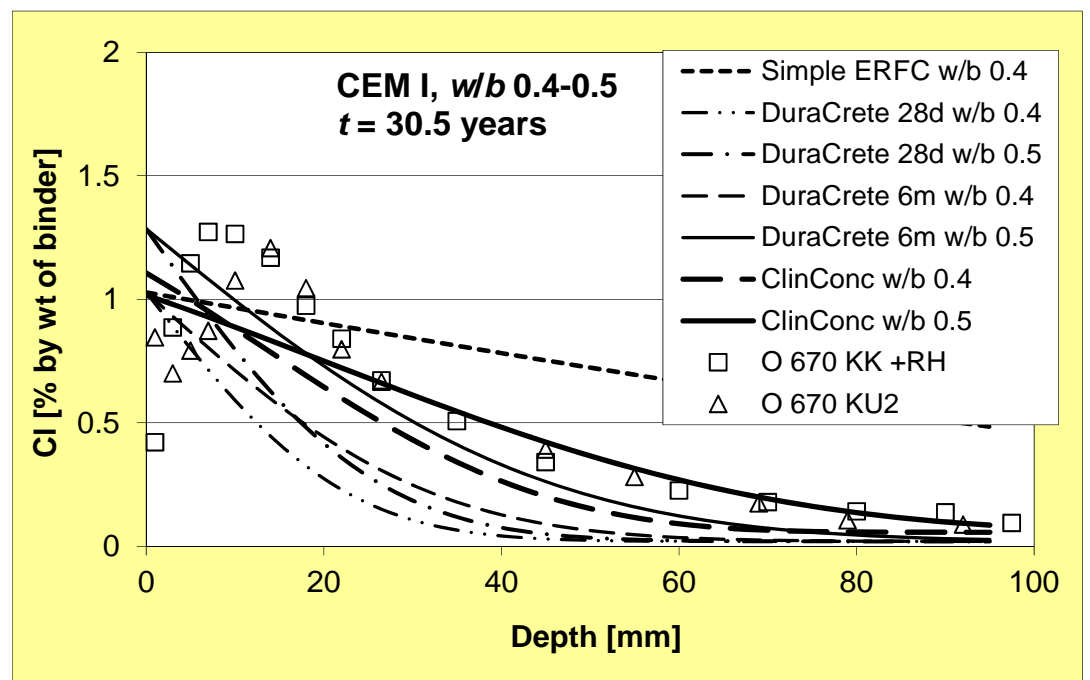


As a summary of the all above cases it can be seen that the simple ERFC model always significantly overestimates the chloride ingress. The DuraCrete model with $D_{\text {RCM6m }} w / b$ 0.5 gives also fairly good prediction, but with $D_{\text {RCM28d }}$ seems to underestimate the chloride ingress in most cases. The reason is probably due to its age factor $(n=0.65)$, which can significantly decrease the apparent diffusion coefficient when $t_{0}$ is 28 days (0.077 years) compared with $t_{0}=0.5$ years, as can be seen in equation (2). Therefore, proper selection of input parameters is the key for the DuraCrete model to achieve a successful prediction. The ClinConc model was previously calibrated against the ten years data from the marine environment (Tang, 2003) and also calibrated against the field data from the road exposure site (Tang and Utgenannt, 2007). It has been shown from the validation against the field data from real concrete road bridges after 25-30 years of exposure that this model in general gives fairly good predictions with the predicted profiles close to the measured ones.

\section{Concluding remarks}

The sensitivity analysis shows that, among different parameters, the age factor $n$ is the most sensitive one, especially when its value is larger than 0.2 . The sensitivity of all the other input parameters is dependent on the ratio $C / C_{\mathrm{s}}$, except for parameter $C_{\mathrm{s}}$, which is constantly equal to 1 , independent of other parameters.

The simple ERFC model significantly overestimates chloride ingress.

The DuraCrete model, if the input parameters are properly selected, e.g., the value of $D_{\text {RCM }}$ measured at $t_{0}=0.5$ years is used, may give a reasonably good prediction, otherwise often underestimates chloride ingress.

The ClinConc model was previously calibrated against ten years field data and, therefore, in general gives fairly good predictions for chloride ingress in the real old bridges after 25-30 years in service under the de-icing salt environment with heavy traffic at high speed. This is a demonstration of importance for a model developer to calibrate his/her prediction model against the field data before the model can be applied to the service life design of real concrete structures.

\section{Acknowledgements}

The financial supports from the Swedish Transport Administration (contract AL90 B 2007:24882) and the Swedish Research Council Formas (contract 2006-1446) are acknowledged. 


\section{References}

Betongföreningen (2007) 'Guidelines for durability design of concrete structures', (in Swedish), Swedish Association of Concrete, Report No. 12, Stockholm.

ChlorTest (2005) 'Modelling of chloride ingress', Resistance of Concrete to Chloride Ingress - From Laboratory Tests to In-Field Performance, WP 4 Report in EU-Project (5th FP GROWTH) G6RD-CT-2002-00855, Borås, Sweden.

DuraCrete (2000) 'General guidelines for durability design and redesign', Probabilistic Performance based Durability Design of Concrete Structures, Report No. 15 in EU-Project (Brite EuRam III) No. BE95-1347, Gouda, The Netherlands.

fib (2006) 'Model code for service-life design', fib bulletin, 1st ed., p.34, Federation International du Beton, Lausanne, Switzerland.

Frederiksen, J.M., Sørensen, H.E., Andersen, A. and Klinghoffer, O. (1997) 'HETEK', in Frederiksen, J.M. (Ed.): The Effect Of The W/C Ratio On Chloride Transport Into Concrete - Immersion, Migration and Resistivity Tests, HETEK Report 54, published by the Danish Road Directorate.

Lindvall, A. (2001) 'Environmental actions and response - reinforced concrete structures exposed in road and marine environments', Licentiate thesis, Dept. of Building Materials, Chalmers University of Technology, Publication No. P-01:3, Gothenburg, Sweden.

Maage, M., Poulsen, E., Vennesland, Ø. and Carlsen, J.E. (1995) 'Service life model for concrete structures exposed to marine environment', LIGHTCON Report No. 2.4, STF70 A94082 SINTEF, Trondheim, Norway.

NordTest (1999) 'Concrete, mortar and cement based repair materials: chloride migration coefficient from non-steady state migration experiments', NT BUILD 492, Helsinki, Finland.

Tang, L. (2003) 'A collection of chloride and moisture profiles from the Träslövsläge field site - From 0.5 up to 10 years investigations', Publication No. P-03:3, Dept. of Building Materials, Chalmers University of Technology, Gothenburg, Sweden.

Tang, L. (2007) 'Service-life prediction based on the rapid migration test and the ClinConc model', in Baroghel-Bouny, V. et al. (Eds.): RILEM Proceedings PRO 047: 'Performance Based Evaluation and Indicators for Concrete Durability', pp.157-164, RILEM Publications.

Tang, L. (2008) 'Engineering expression of the ClinConc model for prediction of free and total chloride ingress in submerged marine concrete', Cem. Concr. Res., Vol. 38, Nos. 8-9, pp.1092-1097.

Tang, L. and Utgenannt, P. (2007) 'Chloride ingress and reinforcement corrosion in concrete under de-icing highway environment - a study after 10 years' field exposure’, SP Report 2007:76, SP Technical Research Institute of Sweden, Borås, Sweden. 